Finisterra, XXXVI, 72, 2001, pp. 115-121

\title{
PAISAGEM - DO URBANO AO RURAL Notas a partir de Lisboa ...
}

Pedro George ${ }^{1}$

A interacção conflitual do homem com a natureza gera e faz evoluir a paisagem. Qual o estado da paisagem portuguesa, em traços gerais? Quais as suas perspectivas de evolução?

Não temos qualquer veleidade de responder a estas perguntas pela via da ciência. Antes se trata aqui de opinar, com q.b. de informação e fundamento, lançando achas para um debate que encontra, nas páginas desta insigne revista, acolhimento em ambiente de eleição.

Estruturámos o conteúdo em três grandes secções que fazemos corresponder a outras tantas grandes tipologias de paisagem: urbana, rural (ou silvestre/agrícola/florestal ou não-urbana (?) - evitamos cuidadosamente o termo «natural») e rurbana (a transição, a margem, a fronteira mais complicada (?!)).

\section{A paisagem urbana pode subdividir-se em:}

- áreas centrais, mais ou menos históricas, onde a degradação dos espaços públicos e do edificado predomina salvo raras e honrosas excepções (Évora, Guimarães?). Mostramo-nos colectivamente incapazes de intervir quer num quer noutros, com a profundidade requerida pela gravidade da situação. Podem, é certo, ver turistas embevecidos com o romantismo da quase-ruína, clamar a beleza triste da cidade antiga, de musgo na parede e humidade no beirado; esse apreço não satisfaz, como também não satisfazem os programas e instrumentos (RECRIA, REHABITA, etc.) até aqui mobilizados para a luta. Onde se poderia intervir com força, por exemplo, a nível de mobiliário urbano, manifesta-se a total incapacidade de elaboração e implementação de uma política para a cidade como um todo, tendo em conta a sua diversidade (e as características de cada bairro), que permitisse, através dos «móveis», criar elos e fios condutores ao longo dos espaços públicos, integrando-os numa estrutura

1 Urbanista/Arquitecto. Professor Auxiliar da Faculdade de Arquitectura da U.T.L. E-mail: almourolpg@netcabo.pt 
que cobrisse toda a cidade e reforçasse, ao mesmo tempo, o sentido de lugar e a pertença a um todo. Ao contrário, grassa o mais crasso incrementalismo, ao sabor dos lobbies dos grandes fabricantes de material.

A qualidade do legado histórico é, ainda assim, aqui, a principal sustentação da qualidade da paisagem a que dá vida, por muito que esteja quase-moribundo o edificado que lhe dá corpo. A revivificação desse edificado é tarefa urgente, mas da qual estão alheados tanto os governos quanto os proprietários e as empresas de construção.

A evolução deste quadro é hoje, na essência, imprevisível mas o avançado estado da doença só pode augurar algo de bom. Sejamos portanto optimistas.

- áreas consolidadas de estatuto variado consoante épocas, habitat social e modos de promoção, manifestam variações de coerência na paisagem. Será lícito aventar a hipótese de uma alta correlação entre a natureza da liderança da operação imobiliária que lhes deu origem e a qualidade actual da paisagem? Onde o Estado promove/regula e organiza a operação conferindo-lhe escala e mobilizando técnicos competentes, o tecido urbano (passando por cima ou através de «estilos» e modos de fazer) é estruturado e coeso dando origem a paisagem que se aguenta no tempo com resiliência e qualidade (Av. Novas, Campo de Ourique, Restelo, Alvalade, Av. de Roma/Arieiro, Olivais, a ainda incógnita de Chelas, Telheiras, Parque Expo, ao que se pode contrapor, Benfica, Amadora, Charneca, Lumiar/Carnide, para utilizar apenas exemplos de Lisboa. Mas porquê a necessidade da presença tutelar do Estado para assegurar uma boa urbanização de raiz? Para além da eterna e quase fatal omnipresença do Estado em tudo o que seja de maior dimensão na nossa história, nos períodos de construção da cidade contemporânea a fraqueza intrínseca da nossa burguesia financeira e industrial fazia com que a tarefa ciclópica da construção de cidade não pudesse ser abraçada em toda a sua plenitude, como em países europeus de capitalismo mais avançado (Inglaterra, França, Alemanha, etc.). Os volumes de capital envolvidos, os ciclos longuíssimos da sua circulação, a natureza incerta da procura final, tudo isto tornava a empresa "areia demais para a nossa camioneta». Nos variados vácuos do processo, a escalas grandes, teria que entrar o Estado. Ao fazê-lo, dentro das normas de racionalidade técnica que são seu apanágio, carreadas por técnicos competentes, dava origem a tecido urbano de boa qualidade, ainda que chagado por inevitáveis vícios de implementação, que são a nossa imagem de marca como povo! Em alternativa, as áreas deixadas à iniciativa privada rapidamente se desmultiplicavam numa miríade de micro-operações individualizadas, à escala do pequeno/médio promotor que era então (e continua ainda a ser!) o principal agente privado da urbanização. Sem directrizes nem planos gerais orientadores e definidores da forma urbana (coisa estranha ao sentir do individualismo lusitano), o agregado das múltiplas micro-operações imobiliárias individuais, nas quais a grande vantagem promocional é justamente fazer-se um prédio «diferente do do vizinho», resulta num tecido urbano desconexo, desgarrado 
e com fraca qualidade urbana e arquitectónica. Sistematicamente sobredensificado (afinal de contas, à administração pública custa-lhe negar aquele pisozito - ou dois, a mais em cada prédio, «coitado do rapaz»!) e com o espaço público reduzido ao mínimo funcionalmente tolerável, a «urbanização» inaugura-se com inevitáveis problemas de estacionamento logo à partida! O grande «shaman» orientador e unificador, que dita as leis desta produção/promoção (o lucro imobiliário), não consegue, sozinho e nas condições que são as nossas, garantir um mínimo aceitável de qualidade nem urbana nem arquitectónica; talvez o consiga tão somente no âmbito do fogo e da construção.

A paisagem urbana destas áreas como daqui se pode deduzir, é variável, do bom ao péssimo se se quiser dar notas à antiga. O futuro carreia potencialidades diferenciadas: Olivais tem a possibilidade de ainda vir a ser um magnífico ambiente urbano, se não continuar a febre densificadora. Benfica, por muito arranjo exterior que se lhe faça e muita árvore que se plante, (acções exigidas pelo habitar de novas classes sociais a tender para o médio-alto) nunca passará do medíocre em termos de vivência urbana; quanto à paisagem... estamos conversados!

- áreas suburbanas/periféricas eventualmente já consolidadas e que se desenvolveram nos últimos 40 anos, no âmbito das profundas alterações que se deram no campo sócio económico e demográfico (desenvolvimento económico em geral, emigração e afluxo aos grandes centros urbanos, mudanças de regime político). Este período, introduz enormes alterações à paisagem urbana, com a constituição das periferias que acolheram os novos habitantes das áreas metropolitanas em gestação. O processo de produção desse novo espaço urbano deu-se essencialmente por três vias:

a via legal das operações de loteamento e construção de prédios, processo acima descrito que, como vimos, cria tecido urbano desequilibrado, desconexo, e desqualificado gerando paisagem de igualmente má qualidade;

a via dos loteamentos clandestinos (hoje AUGI) no qual as características negativas do processo anterior estão ainda mais exacerbadas. O loteador/urbanizador «apertou a tarracha» no máximo, o utente/construtor individualiza e aumenta a construção até ao máximo, resultado: o lote é pequeno, a construção é grande demais para o dito, a rua é minúscula, não há espaços públicos, nem verdes, nem azuis, nem de cor alguma. O resultado é catastrófico e compromete para as próximas gerações milhares de hectares de espaço urbano. A paisagem é serôdia e seca enquanto reflexo da vida urbana, por muito que a população se esforce por humanizá-la. Esforços se têm feito para corrigir as situações mais gritantes, mas o potencial que a situação carrega é pouco e os resultados fracos. Há que visitar e analisar o "centro» da Quinta do Conde (Seixal/Sesimbra) para ter noção clara deste facto;

a terceira via foi o advento da promoção estatal da habitação social sob uma nova forma organizadora. A criação de espaço urbano periférico em operações 
dirigidas fundamentalmente a classes sociais de baixa extracção económica e levadas a cabo sob um clima socio-político de grande tensão, conduziram à alteração dos padrões e formas tradicionais deste tipo de intervenção: adoptaram-se nesta conjugação o uniclassismo, a grande escala, o edifício em colectivo, a localização "erma» em terrenos baratos; a receita resultou num enorme fracasso social tendo todas as áreas sido posteriormente objecto de enormes investimentos suplementares para tentar mantê-las «à tona de água». Como daqui se depreende a paisagem urbana que resulta desta situação não é particularmente qualificada, muito embora a distribuição básica dos espaços públicos livres e dos ocupados por construção possa não ser destituída de capacidades de regeneração, por muito que se alterem as condições de ocupação, de gestão, de manutenção, de presença de equipamentos e arranjos exteriores, etc..

A síntese é simples: a paisagem suburbana dos grandes centros urbanos portugueses é na generalidade má - desestruturada, desequilibrada, desconexa, fragmentada, desinteressante e com o apoio débil de uma arquitectura ela própria sem qualquer interesse ou beleza. Tal é o panorama genérico; exceptuam-se, como é obvio, algumas «ilhas» que, por efeitos do mercado a que se destinam e mérito da promoção escapam a esta lógica terrível.

\section{A paisagem rural ou não urbana}

Compõe-se de várias categorias, a começar pelas áreas de paisagem única, a serem indiscutivelmente e por alargado consenso, objecto de preservação, conservação e, se possível e necessário, até restauro: o topo da Serra da Estrela, o Gerês, a ria de Aveiro, a Pateira de Fermentelos, os Cabos da Roca e Espichel, a Serra de Sintra, etc.

A necessidade de estabelecer critérios a partir da análise da sua geologia, ecologia e paisagem, deriva da eventual conflitualidade inerente à sua eleição e demarcação, sobretudo se existe população nelas residente ou interesses de exploração de recursos físicos. Não parece ser aqui que residem os problemas mais candentes.

Adiante portanto, para as áreas silvestres/agrícolas ou florestais: aqui a paisagem reflecte as formas do cadastro e os modos de produção de cada época de exploração, em conjugação com as técnicas e as condições requeridas pelo produto produzido - o cereal, a uva, a cortiça, o pinheiro, o eucalipto, o borrego, o cabrito, o boi, etc.. A placidez destes processos e a sua perenidade (que não obsta ao progresso técnico) modelou a paisagem durante séculos. De alguns anos a esta parte, o crescimento populacional, a motorização da população e a acrescida acessibilidade a essas mesmas zonas rurais colocam-nos perante a possibilidade de "utilização" por população ou actividades exteriores à sua economia tradicional. A construção de edificação, esparsa ou mais concentrada/primeira ou segunda residência, turismo, armazenagem, etc., ocorre com relativa naturalidade muito para além de, em certas áreas, se 
processar a subdivisão da propriedade e a natural vontade e necessidade do novo agricultor residir na sua propriedade. Qualquer destes movimentos contribui para a transformação da paisagem ao aparecerem, com maior ou menor intensidade (densidade), «pontinhos brancos»: a famosa «ocupação dispersa». Conflito básico entre o desejo de um território paisagisticamente puro sem qualquer nova construção a maculá-lo e as pressões da própria realidade do desenvolvimento e da exploração rural. Também aqui se coloca a distinção entre o direito de propriedade e o direito de construir, distinção essa mal assimilada pela maioria da população portuguesa que, ao exercer descontroladamente este segundo, fabrica uma paisagem "salpicada», uniformizada, e que não reflecte uma compreensão dos diversos elementos que a compõem.

Esta situação virá a colocar-se com veemência no Alentejo, por exemplo, com as alterações ao modo de exploração derivadas do regadio criado pelas águas do Alqueva e consequente subdivisão da propriedade. $\mathrm{O}$ novo proprietário agricultor irá construir uma casinha e um armazém nos seus 5 ou 10 hectares regados? Ou estarão eles associados em cooperativas com sede em aglomerados, onde vivem e de onde partem todas as manhãs para trabalhar nos campos? Ou os empresários espanhóis já compraram toda a terra futuramente irrigada e vão trazer marroquinos sazonais que habitarão barracas nas periferias das vilas alentejanas - quais novos "ratinhos» mas desta vez vindos do Sul? Ou estes cenários misturar-se-ão? Certo é que a paisagem alentejana vai sofrer alterações e aquilo que ali virá a acontecer a um ritmo acelerado, acontece em «câmara lenta» noutras regiões do País. Ninguém (penso!) ousará questionar o direito ao desenvolvimento económico em nome da estabilidade da paisagem alentejana ou outra! (para isso se fazem as infra-estruturas que são já, em si, uma macrotransformação paisagística). No entanto, deseja-se que essa transformação, acelerada ou paulatina, se processe sob ordenamento explicitado, participado, criativo e propositivo, não inibidor de desenvolvimento, antes criando melhores condições para o acolher.

Os instrumentos de planeamento devem portanto prever essas alterações e, ao invés de tentar reprimi-las, encaminhá-las para que resultem em transformações positivas da paisagem.

Não é o caso da legislação tipo RAN e REN, onde a atitude é meramente «na dúvida, ao não se saber o que fazer com a paisagem rural, reserva-se!». Por muito sustentável que seja o método espera-se ansiosamente por instrumentos mais propositivos.

Não é também a posição vigente na maior parte dos concelhos deste país, onde os PDM causticam a ocupação dispersa em nome da paisagem e propõem medidas coercivas para depois criar condições excepcionais de tolerância da mesma que só servem para baralhar e tudo permitir (desde construção contínua ao longo das vias, núcleos de «desenvolvimento turístico», construção de segundas residências encapotadas de sede de exploração agrícola, etc.) na tentativa de evitar conflitualidades políticas e dar vazão a alegadas pulsões humanitárias. 
Em que ficamos então no respeitante à paisagem? Poderá propor-se a ideia de que talvez a ocupação dispersa bem planeada possa gerar uma paisagem equilibrada e harmónica. Isto quer dizer aceitar e propor construção em determinados locais e noutros não! O que, por sua vez e em prol da equidade, só deveria ser implementado com base na perequação dos valores dos ditos direitos de construção.

\section{A paisagem rurbana}

O local do drama, a passagem dos terrenos rurais a urbanos. Aqui as tipologias morfológicas são variadas: do corte abrupto entre tecido urbano denso, com prédios de nove andares e território totalmente rural logo em seguida (estilo São Marcos/Cacém), à ocorrência de densidades decrescentes de mora-

dias unifamiliares que se tornam cada vez mais esparsas em loteamentos com ocupação de parcelas de uso complementar agrícola (Alcochete). Há de tudo um pouco. Esta morfologia variada resulta numa paisagem em desassossego, agitada e instável.

A passagem formal de terrenos de rural a urbano é decretada e delimitada em sede de um PDM. A primeira vaga deste tipo de plano, nos anos 90 a 95, resultou contudo em perímetros urbanos muito amplos - talvez em demasia na vã tentativa de controlar o preço dos terrenos urbanos pelo lado da suposta oferta. No entanto, a passagem de terrenos urbanizáveis da reserva passiva à activa no mercado, depende apenas da vontade do proprietário, o que desde logo, inibe a queda dos preços. Dá-se de forma inevitavelmente desordenada, não coordenada com as reais necessidades de expansão do aglomerado e sim em função das expectativas especulativas do dito proprietário. As operações de loteamento "pipocam» a qualquer momento e em qualquer lugar dentro de vastos perímetros urbanos ao sabor dos desejos dos proprietários. A instância autárquica, em crónica carência de fundos, para além de não ter fundamentos legais válidos para indeferir, muito pelo contrário, acolhe as pretensões caindo na tentação de equilibrar o orçamento e pagar os funcionários com o produto das taxas de urbanização, contribuições autárquicas, sisas, etc. Ao assim fazer põe ainda mais óleo no fogo do completo desordenamento do processo de urbanização. Ao governo autárquico está acometida a tarefa de zelar pelo bom uso e transformação do solo do País; em consequência confere-se-lhe o poder de licenciar e receber por isso mas, ao mesmo tempo, a matriz do seu financiamento provoca a penúria constante e induz a tentação de mercantilizar o gesto ordenador, destituindo-o assim do seu sentido primordial. Parece-nos indubitável que a forma de financiamento das autarquias tem efeitos perversos no processo de urbanização, contribuindo fortemente para o seu desordenamento. Incapa-cidade ordenadora das autarquias, cujo papel na passagem de solos rurais a urbanos se limita à definição de quem vai beneficiar das famosas maisvalias (os que têm a benesse do «urbanizável»); especulação do proprietário na 
realização das chorudas mais-valias urbanas; complete-se o quadro com o capital financeiro na ponta final a incentivar a família portuguesa a entrar no mercado da habitação a altos preços através de sobre-endividamento e, como tal, acelerando a passagem à activa de mais e mais solo também a altos preços: temos todos os ingredientes para uma desordenada urbanização nas franjas do território urbano, gerando paisagem de fraquíssima qualidade, para já não falar nos elevados custos de infraestruturação urbana.

Requerer, em sede de revisão de PDM, a redução de perímetros urbanos ou da capacidade edificatória por eles contida é politicamente de alto risco. Os compromissos legais (direitos efectivamente adquiridos) políticos e pessoais são de grande envergadura. De qualquer forma os resultados de tal exercício seriam duvidosos.

Mais sensato seria criar condições técnicas e legais para poder urbanizar dentro dos actuais perímetros com qualidade e equilíbrio; para tal haveria que poder programar (no PDM?) a «entrada em campo» dos solos a urbanizar na prática. Posteriormente captar as mais valias, pela via fiscal ou pela expropriação, para os cofres autárquicos, melhorando assim o financiamento municipal. Essa captura permitiria controlar e, até, ir baixando lentamente o preço do solo urbanizado e, consequentemente, da habitação. Talvez, mas apenas talvez, se conseguisse então criar paisagem peri-urbana de melhor qualidade.

A interacção conflitual do homem com a natureza gera e faz evoluir a paisagem. Essa interacção conflitual contém processos socio-económicos e políticos cuja lógica não é espacial - ou pelo menos enquanto o espaço é espaço e não mercadoria. A paisagem resultante é, afinal, sobre e sub determinada. Ao dela falarmos, falamos de um «ersatz» dissimulador de outra realidade quiçá mais complicada de lidar em directo. Não tomemos a núvem por Juno na discussão da paisagem. 